\title{
Study on Outdoor Thermal Comfort in the Transitional Season of Hefei
}

\author{
Jinwei $\mathrm{Li}^{1}$, Lilin Zhao ${ }^{1}$, Zheyao Peng ${ }^{1}$, Zijian Wang ${ }^{1}$ and Taotao Shui ${ }^{1,2^{*}}$ \\ ${ }^{1}$ School of Environment and Energy Engineering, Anhui Jianzhu University, Hefei, Anhui,230022, China \\ ${ }^{2}$ BIM Engineering Center of Anhui Province, Anhui Jianzhu University, Hefei, Anhui, 230022, China
}

\begin{abstract}
In order to study the outdoor thermal comfort during the transition season in Hefei, a university in Hefei adopted a combination of field environmental measurements and questionnaires to study the changes in thermal sensation and thermal comfort of outdoor people before and after the transition season. The rankings of the effects of temperature, wind speed, humidity, and solar radiation on human thermal comfort were obtained through surveys, and the proportion of each parameter's influence on human thermal comfort was analyzed. The relationship between thermal sensation and thermal comfort was analyzed, and the application was established through regression analysis Prediction model of thermal sensation in autumn and winter outdoor environment in Hefei area.
\end{abstract}

\section{Introduction}

With the continuous decline of environmental quality and the continuous improvement of people's living standards, people's requirements for outdoor thermal environment are also getting higher and higher. The main meteorological parameters that affect the thermal comfort of the human body in the outdoor environment are temperature, wind speed, humidity, and solar radiation. At the same time, compared with the more stable indoor thermal environment, these outdoor meteorological environments have a wider range of changes and more severe fluctuations [1]. Therefore, the outdoor thermal environment will have a more severe impact on the people's thermal sensation and thermal comfort.

In fact, domestic scholars and abroad have done a lot of research on thermal comfort. Research by Nikolopoulou M, and Lykoudis S confirms the close relationship between climate and comfort conditions. Air temperature and solar radiation are important determinants of comfort [1]; Kenny N A al. Evaluated COMFA's outdoor thermal comfort model for subjects with moderate to strenuous exercise [2]; Qian W took PMV Based on the model, the outdoor thermal environment comfort evaluation model OTCD was derived [3]; Chen X et al. Used a combination of field environmental measurement and questionnaire survey to analyze people's satisfaction with meteorological parameters and overall in winter outdoor environment in Harbin Comfort [4]. However, the current research on thermal comfort in China is mainly focused on the research of human comfort in indoor steady-state environment. There is relatively little research on outdoor thermal comfort, especially in the thermal environment with dynamic changes in the transition season.

The current research on human thermal comfort in Hefei area mainly focuses on indoor environment [5]. There is less research on outdoor thermal comfort, especially human thermal comfort in the transition season, and it cannot provide corresponding guidance for the outdoor thermal environment design in Hefei. Therefore, this study selects autumn as the more typical transition season period in Hefei, and also covers the results of some winter periods after autumn for comparative analysis. By studying the influencing factors of outdoor thermal comfort before and after the transition season in Hefei, and here Based on the establishment of a thermal sensation prediction model, some improvement measures are proposed to improve the comfort of Hefei area, which also has important guiding significance for rationally improving the quality of life of residents in Hefei area through architectural planning.

\section{Research method}

\subsection{Questionnaire survey method}

In order to study the outdoor thermal comfort situation before and after the transition season in Hefei, this research conducted 33 questionnaires from September 23, 2019 to January 4, 2020, and sent and collected 638 valid questionnaires. According to the climatic data of Hefei City, the autumn of Hefei City is from September 21 to

\footnotetext{
*Corresponding author's e-mail: shui_taotao@126.com
} 
November 15, and the winter is from November 16 to March 25. Therefore, in this survey, September 23 to November 11 is the autumn phase, and November 18 to January 4 the following year is the winter phase.

The survey was conducted at a university in Hefei. The survey objects were undergraduates at the school. The survey mainly investigated the physiological parameters, dressing conditions, activity levels, and their thermal sensations and thermal comfort votes of the current environment. In order to facilitate the respondents to fill out the questionnaire in a timely and effective manner, this questionnaire is mainly issued by electronic questionnaires, as shown in Figure 1.

At present, the more commonly used thermal sensation vote TSV (Thermal Sensation Vote) is divided into 7 scales. However, considering the climate characteristics of Hefei area and some extreme conditions. Therefore, this time the thermal sensory scale is 9 levels, and the scale division is shown in Table 1 . The thermal comfort voting TCV (Thermal Comfort Vote) uses a 7-level division scale. See Table 2.

Table 1. TSV scale.

\begin{tabular}{cccccccccc}
\hline TSV & $\begin{array}{c}\text { Very } \\
\text { cold }\end{array}$ & Cold & Cool & $\begin{array}{c}\text { Slightly } \\
\text { cool }\end{array}$ & Neural & $\begin{array}{c}\text { Slightly } \\
\text { warm }\end{array}$ & Warm & Hot & $\begin{array}{c}\text { Very } \\
\text { Hot }\end{array}$ \\
\hline $\begin{array}{c}\text { TSV } \\
\text { value }\end{array}$ & -4 & -3 & -2 & -1 & 0 & 1 & 2 & 3 & 4 \\
\hline
\end{tabular}

Table2. TCV scale.

\begin{tabular}{cccccccc}
\hline TCV & $\begin{array}{c}\text { Very } \\
\text { uncomfortable }\end{array}$ & Uncomfortable & $\begin{array}{c}\text { Slightly } \\
\text { Uncomfortable }\end{array}$ & Neutral & $\begin{array}{c}\text { Slightly } \\
\text { comfortable }\end{array}$ & comfortable & $\begin{array}{c}\text { Very } \\
\text { uncomfortable }\end{array}$ \\
\hline $\begin{array}{c}\text { TCV } \\
\text { value }\end{array}$ & -3 & -2 & -1 & 0 & 1 & 2 & 3 \\
\hline
\end{tabular}

\subsection{Data acquisition method}

The data collection uses the Jinzhou Sunshine PC-8 IoT Meteorological Environment Station. The main data collected by small weather stations are ambient

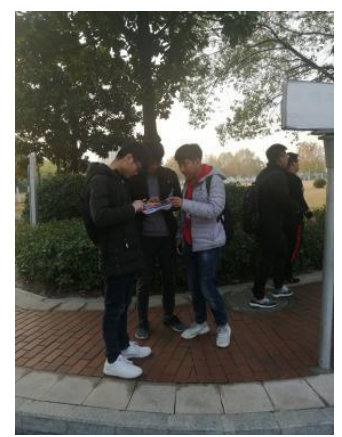

Figure 1.Survey respondents fill out the questionnaire. temperature $(\mathrm{T})$, wind speed $(\mathrm{W})$, relative humidity $(\mathrm{R})$, and total solar radiation (S), and the current weather data is set to be recorded every 5 minutes. The weather station installation location is shown in Figure 2.

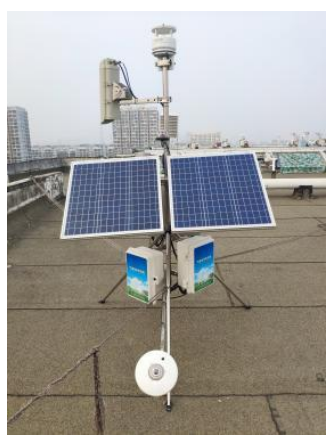

Figure 2. Weather station layout.

Table 3. Weather station parameters.

\begin{tabular}{llll}
\hline \multicolumn{1}{c}{$\begin{array}{c}\text { Meteorological } \\
\text { parameters }\end{array}$} & \multicolumn{1}{c}{ Measurement range } & \multicolumn{1}{c}{ Resolution } & \multicolumn{1}{c}{ Accuracy } \\
\hline Ambient temperature & $-50 \sim+85^{\circ} \mathrm{C}$ & $0.1^{\circ} \mathrm{C}$ & $\pm 0.1^{\circ} \mathrm{C}$ \\
Relative humidity & $0 \sim 100 \%$ & $0.1 \%$ & $\pm 2 \%(\leq 80 \%) ;$ \\
& & & $\pm 5 \%(>80 \%)$ \\
Total radiation & $0 \sim 2000 \mathrm{~W}$ & $1 \mathrm{~W} / \mathrm{m}^{2}$ & $\leq 5 \%$ \\
Wind direction & $0 \sim 360^{\circ}$ & $3^{\circ}$ & $\pm 3^{\circ}$ \\
Wind speed & $0 \sim 75 \mathrm{~m} / \mathrm{s}$ & $0.1 \mathrm{~m} / \mathrm{s}$ & $\pm(0.3+0.03 \mathrm{~V}) \mathrm{m} / \mathrm{s}$ \\
\hline
\end{tabular}

\section{Survey results and data analysis}

\subsection{Proportion analysis of subjective thermal comfort impact}

Figures 3 (a) and (b) show the voting statistics of the impact of the outdoor meteorological environment on human subjective thermal comfort. It can be seen that during the autumn and some winters of the survey, the respondents had the same order of influence on the 
thermal comfort of the respondents regarding the four meteorological factors of temperature, humidity, wind speed and solar radiation. The specific ranking result is temperature $>$ Wind speed $>$ radiation $>$ humidity. Specifically, the majority of people choose temperature as the main influencing factor in the autumn and winter seasons, reaching $68.89 \%$ and $73.4 \%$, respectively, indicating that people think that the temperature has the greatest impact on human comfort in the autumn and winter. The impact of wind speed on human comfort ranks second in the autumn and winter seasons. The

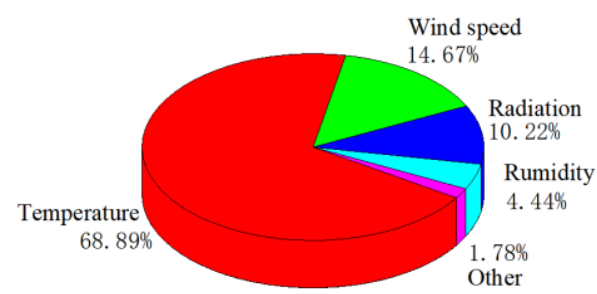

(a) Autumn reason is that the outdoor temperature in Hefei dropped significantly during the survey, so people 's perception of their own heat loss has increased. When the wind speed changes slightly, people will feel uncomfortable due to the loss of a small amount of their own heat. Compared with temperature and wind speed, the influence of solar radiation on people's comfort in autumn and winter is limited, accounting for only $10.22 \%$ and $5.85 \%$ respectively. Humidity is the factor that has the least impact on people's comfort.

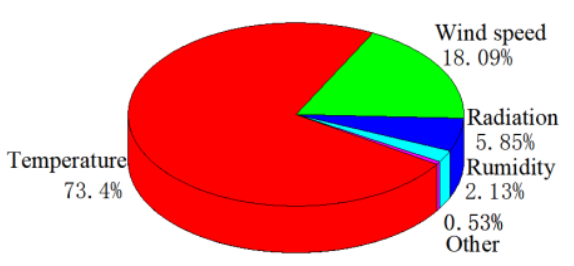

(b) Winter

Figure 3.Percentage of vote that has the greatest impact on human thermal comfort: (a) Autumn; (b) Winter.

\subsection{The relationship between thermal comfort and thermal sensation}

Figures 4 (a) and (b) show the changes in thermal sensation and thermal comfort during the survey in autumn and some winters. It can be seen from the figure that the human body's thermal sensation in autumn is mainly concentrated between "cool" and "slightly warm" and the comfort level this time slightly fluctuates, relevant to the climate change in Hefei. Cold waves often invade at the end of autumn, and the temperature drops sharply, and the human body will feel "cool", at the same time, people will feel uncomfortable, but the overall thermal comfort is still in a relatively stable state. In the

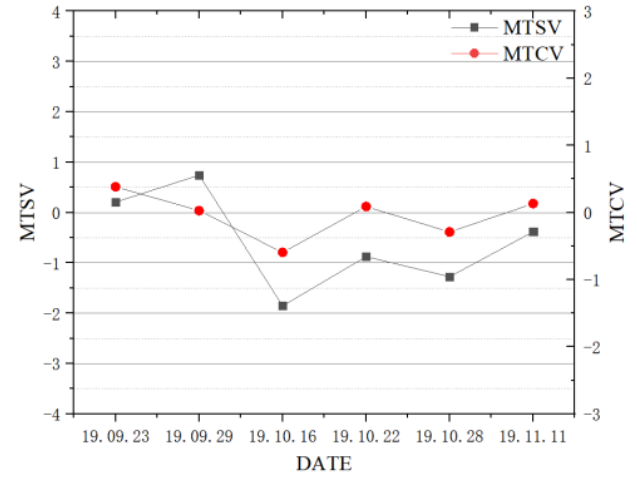

(a) Autumn winter, the human body feels that the votes are all negative, concentrated between "slightly cool" and "cold". During the transition from late autumn to early winter, the thermal comfort changes more drastically, and the human thermal comfort vote appears as "uncomfortable", and this discomfort persists for a period of time. In mid-December, the thermal sensation vote was concentrated between "slightly cool" and "cool", and the thermal comfort vote was mainly focused on "neutral" and "slightly uncomfortable". Compared with the winter season, the thermal comfort was moderated. The human body's adaptability to climate change is related to adding clothes to keep warm.

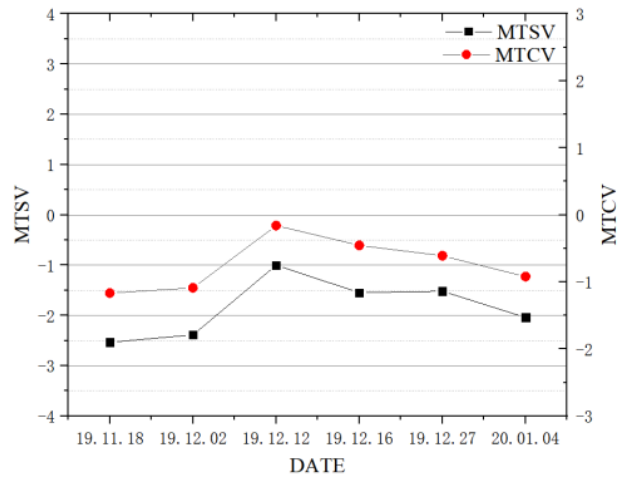

(b) Winter

Figure 4.Relationship between thermal sensation and thermal comfort over time: (a) Autumn; (b) Winter.

In order to explore the relationship between thermal sensation and thermal comfort in the transition season, we averaged the thermal comfort voting values corresponding to the same thermal sensation voting in the same season, and obtained the correspondence of each thermal sensation voting in the same season. The average thermal comfort vote and a fitting analysis are performed, as shown in Figure 5, thereby reflecting the relationship between the change in thermal sensation and average thermal comfort vote.

As can be seen from Fig. 5, in autumn, When the thermal sensation are "very cold", "cold", "cool", "hot" 
and "very hot", people will feel uncomfortable. In winter, when people's thermal sensation are "very cold", "cold", "cool" and "slightly cool", people will feel uncomfortable. At the same time, it can be found that when the thermal sensation is "slightly cool", autumn comfort is better, but in winter people are uncomfortable. When people feel thermally "neutral", people generally feel comfortable in both autumn and winter. And when people 's thermal sensation rises slightly again, the two fitting curves produce an intersection point. At this time, people 's thermal comfort is the same in autumn and winter. Before that, no matter what thermal sensation state people were in, people's comfort is always better in autumn than in winter. After this point, people 's thermal comfort in winter is always better than in autumn. At the same time, thermal comfort in autumn begins to decline along with thermal sensation but remains comfortable until the thermal sensation is slightly higher than "warm", people began to feel uncomfortable, and in the winter people remained comfortable.

According to the analysis of specific conditions, in the autumn of the transition season, people's thermal comfort will fluctuate significantly with the change in thermal sensation. When the thermal sensation is slightly lower than "slightly cool" or higher than "warm", people will feel uncomfortable, and when the thermal sensation is in between, people's comfort is always good. After the transition to winter, people's thermal comfort will always increase when the thermal sensation rises due to the low temperature. As long as the thermal sensation is slightly higher than "slightly cool", people will feel comfortable.

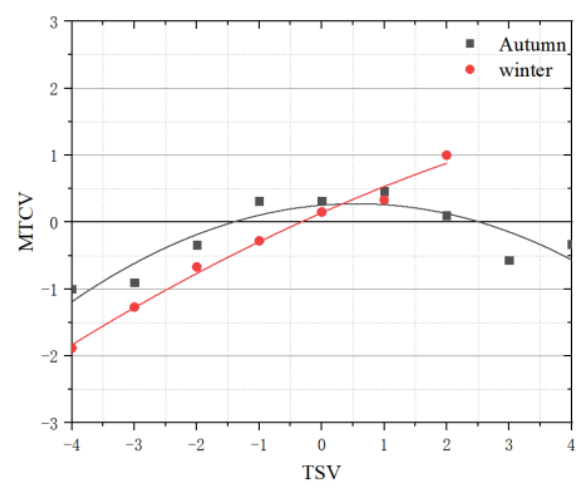

Figure 5.Relationship between thermal sensation and thermal comfort in autumn and winter.

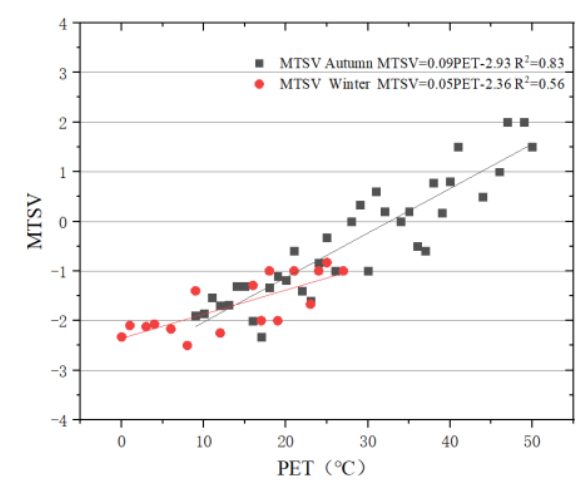

Figure 6.PET prediction thermal sensation model.

\section{Thermal sensation model establishment}

Gagge et al. Proposed a new effective temperature ET* in 1971. After considering the thermal resistance and activity of clothing, a well-known two-node model was proposed, and based on this, the standard effective temperature SET* was also proposed, 1984. Hoppe et al. Proposed physiologically equivalent temperature PET. SET* and PET are commonly used in the evaluation of outdoor thermal comfort. Therefore, in this study, these two indicators are used to establish a thermal sensation prediction model to evaluate people's outdoor thermal comfort.

\subsection{PET and SET* predictive thermal sensation models}

Scatter plots were drawn using physiologically equivalent temperature PET and standard effective temperature $\mathrm{SET}^{*}$ as independent variables, and average thermal sensation vote MTSV as the dependent variable (as shown in Figures 6 and 7), and the two results were obtained by linear fitting. Equations (1), (2), (3), and (4) are the regression equations of thermal sensation in autumn and winter.

$$
\begin{array}{lcc}
\text { Autumn } & \text { MTSV }=0.05 P E T-2.36 & R^{2}=0.83 \\
\text { Winter } & \text { MTSV }=0.09 P E T-2.93 & R^{2}=0.56 \\
\text { Autumn } & \text { MTSV }=0.09 S E T^{*}-2.24 & R^{2}=0.82 \\
\text { Winter } & \text { MTSV }=0.06 S E T^{*}-2.22 & R^{2}=0.66
\end{array}
$$

It can be seen from Fig. 6 that the slope of the relationship in autumn is large, indicating that the change rate of thermal sensation relative to PET is large, and that in winter is small, when the amount of change in PET is the same, the thermal sensation in winter is small.

It can be seen from Fig. 7 that the slope of the relationship in autumn is larger than that in winter, which indicates that the change rate of thermal sensation relative to SET * in autumn is greater than that in winter. The change in thermal sensation is greater than that in winter.

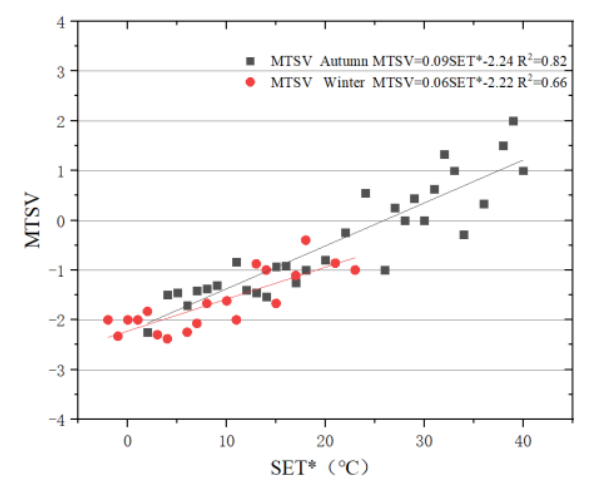

Figure 7.SET * prediction thermal sensation model. 


\subsection{Thermal parameter prediction model for meteorological parameters}

In this study, the outdoor meteorological parameters studied are mainly temperature $T$, relative humidity $R H$, solar radiation $S$, and wind speed $W$. In order to understand the influence of these outdoor meteorological environmental parameters on human thermal sensation, and the degree of influence of various meteorological parameters on human thermal sensation. This paper uses these meteorological parameters as independent variables and human thermal sensation voting as the dependent variable to perform a multiple regression analysis to obtain a model for predicting human thermal sensation using meteorological parameters. The prediction model is given as follows:

$$
\begin{gathered}
T S V=0.126 T+0.0005 R H+0.011 S-0.073 W-3.5712 \\
\left(\mathrm{R}^{2}=0.402\right)
\end{gathered}
$$

where $T S V$ is the human thermal sensation vote; $T$ is the outdoor temperature, ${ }^{\circ} \mathrm{C} ; R H$ is the relative humidity, $\%$; $S$ is the solar radiation, $\mathrm{W} / \mathrm{m}^{2} ; W$ is the wind speed, $\mathrm{m} / \mathrm{s}$.

According to the prediction model, there is a positive correlation between temperature, solar radiation and humidity in autumn and winter and human thermal sensation. Among them, humidity has the least influence on thermal sensation voting, while temperature has the greatest effect on thermal sensation voting. Only the wind speed has a negative correlation with the human thermal sensation.

\section{Conclusions}

1) During the survey, people ranked the importance of environmental factors affecting comfort: temperature, wind speed, solar radiation, relative humidity.

2) Thermal comfort changes drastically with thermal sensation, the degree of change is much greater in autumn than in winter. In autumn, people's thermal comfort and thermal sensation have a simple quadratic function correlation. In winter, people's thermal comfort and thermal sensation are positively correlated. With the increase in thermal sensation, people's thermal comfort is on the rise.

3) A mathematical model for predicting thermal sensation using PET and SET * in Hefei area in autumn and winter was obtained by linear fitting. In addition, a human thermal sensation prediction model based on meteorological parameters was established through multiple regression.

\section{Acknowledgments}

This research is funded by Anhui University of Architecture for Undergraduate Innovation and Entrepreneurship Project (201910878061) and Natural Science Foundation of the Anhui Higher Education Institutions of China (KJ2019A0762).

\section{References}

1. Nikolopoulou M, Lykoudis S. Thermal comfort in outdoor urban spaces: Analysis across different European countries[J]. Building and Environment,2005,41(11).

2. Kenny N A, Warland J S, Brown R D, Gillespie T G Part A: Assessing the performance of the COMFA outdoor thermal comfort model on subjects performing physical activity[J]. International Journal of Biometeorology,2009,53(5).

3. Qian W. Study on the Comfort of Urban Outdoor Thermal Environment [D]. Chongqing University, 2003.

4. Chen X, Liu J, Zhang P, Xue P, Liu L. Research on outdoor thermal comfort in urban areas in severe cold areas in winter [J]. Architectural Science, 2017, 33 (10): 8-12.

5. [5] Zhang Q. Research on Indoor Thermal Environment of University Dormitories in Hefei [D]. Hefei University of Technology, 2012. 